\title{
ESTABILIDADE DO LEITE AO ÁLCOOL AINDA PODE SER UM INDICADOR CONFIÁVEL?
}

\author{
IS ETHANOL STABILITY OF MILK A RELIABLE TEST?
}

\author{
Rafael Fagnani ${ }^{1 *}$ \\ Ana Paula Pavão Battaglini² \\ Vanerli Beloti \\ João Paulo Andrade de Araújo ${ }^{1}$ \\ 1 Universidade do Norte do Paraná, Londrina, PR, Brasil. \\ 'Universidade Estadual de Londrina, Londrina, PR, Brasil. \\ *Autor para correspondência - rafaelfagnani@hotmail.com
}

\begin{abstract}
Resumo
As provas de estabilidade alcoólica e acidez Dornic ainda são amplamente utilizadas em diversos países, mensurando indiretamente a qualidade microbiológica do leite. Porém, outros fatores além da contagem de micro-organismos alteram essa relação, causando um efeito confundidor nesses testes de triagem. O objetivo deste estudo foi relacionar o $\mathrm{pH}$, a contagem bacteriana total, a acidez Dornic e a porcentagem de lactose em leites estáveis e instáveis ao álcool. Foram analisadas 322 amostras de leite, sendo classificadas em ácidas, normais ou instáveis não ácidas, segundo os testes de resistência alcoólica e acidez titulável. Diferentemente de leites normais ou ácidos, não existe relação entre pH, CBT e acidez Dornic em amostras de leite que possuem instabilidade alcoólica sem acidez adquirida. Nesse tipo de leite, valores de pH entre 6,6 e 6,8 são acompanhados de contagens bacterianas mais baixas, de até $10^{5}$ bac. $\mathrm{mL}^{-1}$, e porcentagens de lactose mais altas, de até $4,5 \%$. Conforme a CBT aumenta, a porcentagem de lactose ou o $\mathrm{pH}$ tendem a diminuir, porém não necessariamente juntos. Esse comportamento faz com que o teste do álcool não seja um indicador confiável para a qualidade do leite, devendo ser aplicado sempre em conjunto com outras provas que auxiliem no diagnóstico de acidez bacteriana e/ou resistência térmica, como titulação do ácido lático, mensuração de $\mathrm{pH}$ e teste da fervura.
\end{abstract}

Palavras-chave: alizarol; etanol; instabilidade.

\begin{abstract}
The alcoholic stability of milk is a current problem in many countries that still use the alcohol test to measure the microbiological quality of milk. Beyond microbiological acidity, many factors can also affect the alcoholic stability of milk, leading to a confounding effect in alcohol test and industrial losses. The present study aimed to evaluate the relationship between $\mathrm{pH}$, bacterial count, Dornic acidity, lactose percentage and ethanol stability of milk. The samples comprised fresh raw milk from 322 dairy farms from Parana state. According to the results of the $72^{\circ}$ ethanol test and the Dornic acidity test, the samples received the following classification: stable milk, acidic milk, or unstable milk to ethanol. There was no relationship among $\mathrm{pH}$, Dornic acidity and microbiological count in samples of milk that were unstable to alcohol test. Unstable milk to ethanol has $\mathrm{pH}$ values ranging between 6.6-6.8 with low microbiological count (less than $10^{5}$ cell. $\mathrm{mL}^{-1}$ ) and higher lactose percentages (up to $4.5 \%$ ). As bacterial count increase, the lactose percent tends to decrease, but not necessarily together. This feature makes the alcohol test unreliable, and the use of other parameters
\end{abstract}


is strongly recommended such as thermal stability, lactic acid titration, $\mathrm{pH}$, and clot-on-boiling test. Keywords: alizarol; ethanol; instability.

Enviado em: 10 setembro 2014

Aceito em: 30 maio 2016

\section{Introdução}

A relação entre $\mathrm{pH}$, ácido lático e número de micro-organismos foi completamente elucidada durante a década de 1920 e até hoje é explorada pela tecnologia de alimentos ${ }^{(1)}$. Essa relação ainda serve de base legal para provas que mensuram a acidez do leite brasileiro, como a acidez na escala Dornic, um parâmetro indireto para $\mathrm{pH}$ e contagem de micro-organismos ${ }^{(2)}$. Outras provas indiretas da acidez também são utilizadas para mensurar a qualidade do leite brasileiro, como a prova do álcool/alizarol.

Entretanto, alguns fatores podem interferir na relação entre $\mathrm{pH}$, ácido lático e número de microorganismos. Um deles é a presença de psicrotróficos, que não metabolizam lactose em ácido lático, fazendo com que altas contagens bacterianas nem sempre sejam acompanhadas de $\operatorname{acidez}^{(3)}$. Outro fator que também interfere nessa relação é o fenômeno do leite instável não ácido (LINA), que apresenta instabilidade na prova do álcool sem possuir acidez de origem microbiológica ${ }^{(4-5)}$.

Oscilações em alguns componentes lácteos, como o balanço salino, lactose, ureia e cálcio livre podem estar relacionadas à estabilidade alcoólica. Isso faz com que outras variáveis, além da acidez microbiológica, influenciem a prova do álcool/alizarol, podendo haver descarte desnecessário de leite cru, no momento da sua coleta ou recepção pela indústria.

O LINA é um problema atual em muitos países que ainda utilizam a prova do álcool para mensurar a qualidade do leite, como Brasil, Uruguai, Cuba e Argentina ${ }^{(6)}$. A instabilidade do leite ao álcool também gera problemas tecnológicos na fabricação de licores cremosos, como o fat-plug, e menor vida de prateleira devido à instabilidade da emulsão ${ }^{(7)}$.

As interações entre contagem bacteriana total e acidez podem diferir em leites instáveis ao álcool e sem acidez microbiológica. Assim, estudos que relacionam acidez e contagem de micro-organismos em LINA podem gerar dados para indústrias e produtores, auxiliando-os a prever alguns fatores que afetam a qualidade do leite, otimizando a produção e o beneficiamento de produtos lácteos.

$\mathrm{O}$ objetivo deste estudo foi relacionar o $\mathrm{pH}$, a contagem bacteriana total, a acidez Dornic e a porcentagem de lactose do leite instável não ácido, comparando-o com o leite normal e o leite ácido.

\section{Material e Métodos}

O estudo foi conduzido no Centro Mesorregional de Excelência e Tecnologia do Leite do Paraná Norte Central, na Universidade Estadual de Londrina, de maio a julho de 2012. Nesse período, foram analisadas 322 amostras de leite cru coletadas diretamente de latões em seis municípios da região norte do estado do Paraná.

As amostras foram homogeneizadas com auxílio de uma concha flambada e aproximadamente 300 $\mathrm{mL}$ foram coletados. Uma alíquota de $200 \mathrm{~mL}$ foi armazenada em bolsas plásticas estéreis e o restante foi igualmente dividido em frascos de polietileno, mantidos sob refrigeração em caixas isotérmicas com gelo reciclável.

As bolsas plásticas estéreis foram encaminhadas para o laboratório, onde foram realizadas a prova do álcool $72^{\circ}(\mathrm{v} / \mathrm{v})$, titulação de acidez pelo método Dornic ${ }^{(8)}$ e determinação do $\mathrm{pH}$, utilizando-se $\mathrm{pH}$ metro portátil HANNA HI8424.

As amostras foram classificadas em: LINA, quando apresentaram acidez titulável de 14 a $18^{\circ} \mathrm{D}$ e 
precipitação na prova do álcool $72^{\circ}(\mathrm{v} / \mathrm{v})$; leite normal, com acidez titulável entre 14 e $18^{\circ} \mathrm{D}$ e não precipitados na prova do álcool $72^{\circ}(\mathrm{v} / \mathrm{v})$; e ácidos, leites com acidez titulável acima de $18^{\circ} \mathrm{D}$ e precipitação na prova do álcool.

Os frascos de polietileno continham bronopol para a determinação da composição centesimal pela metodologia de infravermelho ${ }^{(9)}$ e azidiol para a contagem total de bactérias por citometria de fluxo ${ }^{(10)}$. Os frascos foram encaminhados ao laboratório da Associação dos Produtores e Criadores de Bovinos da Raça Holandesa (APCBRH), Curitiba-PR, onde a porcentagem de lactose e contagem bacteriana total (CBT) foram mensuradas.

$\mathrm{O}$ delineamento experimental foi inteiramente ao acaso e as variáveis analisadas foram $\mathrm{pH}$, porcentagem de lactose e contagem bacteriana total (CBT). A CBT que não apresentou distribuição normal pelo teste de Lilliefors foi normalizada por transformação logarítmica. Os dados foram submetidos à correlação de Spearman para cada comportamento do leite (normal, ácido e LINA) no software Statistica versão 7.0.

\section{Resultados e Discussão}

Das amostras analisadas, $92(28,6 \%)$ foram classificadas como normal, $138(42,8 \%)$ como LINA e $92(28,6 \%)$ como leite ácido. Essa ocorrência foi semelhante à encontrada por Battaglini et al. ${ }^{(6)} \mathrm{e}$ Zanella et al. ${ }^{(11)}$, com ocorrência variando entre 30 e $40 \%$.

A ocorrência de LINA costuma sofrer influência da sazonalidade. A maioria dos autores relata frequências mais elevadas no outono, apontando a restrição alimentar associada à rebrota de pastagens como possível causa ${ }^{(12)}$. Dependendo da estação do ano, a composição físico-química e microbiológica do leite normal pode diferir da composição do LINA; no entanto, essa diferença não está necessariamente associada ao fenômeno da instabilidade sem acidez adquirida, uma vez que somente as estações do ano já são suficientes para causarem diferenças nesses componentes ${ }^{(6)}$. Outros fatores se relacionam com as causas do LINA, como à sanidade da glândula mamária, que tem sua permeabilidade alterada em patologias ou estágios da lactação. Os desequilíbrios ácido-base dos animais também podem promover a instabilidade ${ }^{(13)}$.

Vacas com alcalose respiratória têm alta probabilidade de produzir leite com instabilidade alcoólica ${ }^{(14)}$. Para compensar esse distúrbio, o organismo do animal aumenta a excreção de bicarbonato no sangue. Esse excesso acaba sendo excretado pelo leite, promovendo o aumento da instabilidade alcoólica por dois mecanismos: o primeiro é o aumento do $\mathrm{pH}$, que faz a solubilidade dos sais diminuírem, aumentando as chances de precipitação na prova do álcool. O segundo fator é que maiores quantidades de $\mathrm{HCO}_{3}{ }^{-}$aumentam a concentração de $\mathrm{CO}_{3}{ }^{2-}$, possibilitando a formação de sais carbonatados com cátions $\left(\mathrm{Ca}^{2+}, \mathrm{K}^{+}, \mathrm{Na}^{+}\right)$, levando à precipitação de sais e, consequentemente, a maiores chances de precipitarem na prova do álcool ${ }^{(15)}$.

As médias, desvio e erro padrão da lactose, CBT, acidez Dornic e $\mathrm{pH}$ para cada comportamento do leite estão na Tabela 1. No teste de Fisher, não houve diferença de médias ( $p>0,05)$ entre os grupos "normal" e "LINA" para nenhum componente analisado. Contudo, no grupo classificado como "ácido", as médias de todos os componentes diferiram $(\mathrm{p}<0,05)$ dos demais grupos, exceto para a porcentagem de lactose.

Para o leite normal houve uma fraca porém significativa $(\mathrm{p}<0,05)$ correlação entre a CBT e a porcentagem de lactose, com coeficiente de correlação de Spearman $r=-0,20$ (Figura 1), ou seja, para cada ciclo logarítmico na CBT houve um decréscimo de $0,05 \%$ na lactose. As demais variáveis do leite normal não se correlacionaram $(p>0,05)$ entre si. Nessa faixa entre 14 e 18 graus Dornic, as variações da CBT e do $\mathrm{pH}$ não acompanharam a acidez titulável, mesmo com contagens bacterianas superiores à $10^{7}$ bac. $\mathrm{mL}^{-1}$. 
Tabelal: Média, desvio e erro padrão de acidez Dornic, $\mathrm{pH}$, porcentagem de lactose e contagem bacteriana total (CBT) para leites normais, ácidos e instáveis não ácidos (LINA) da região norte do Paraná.

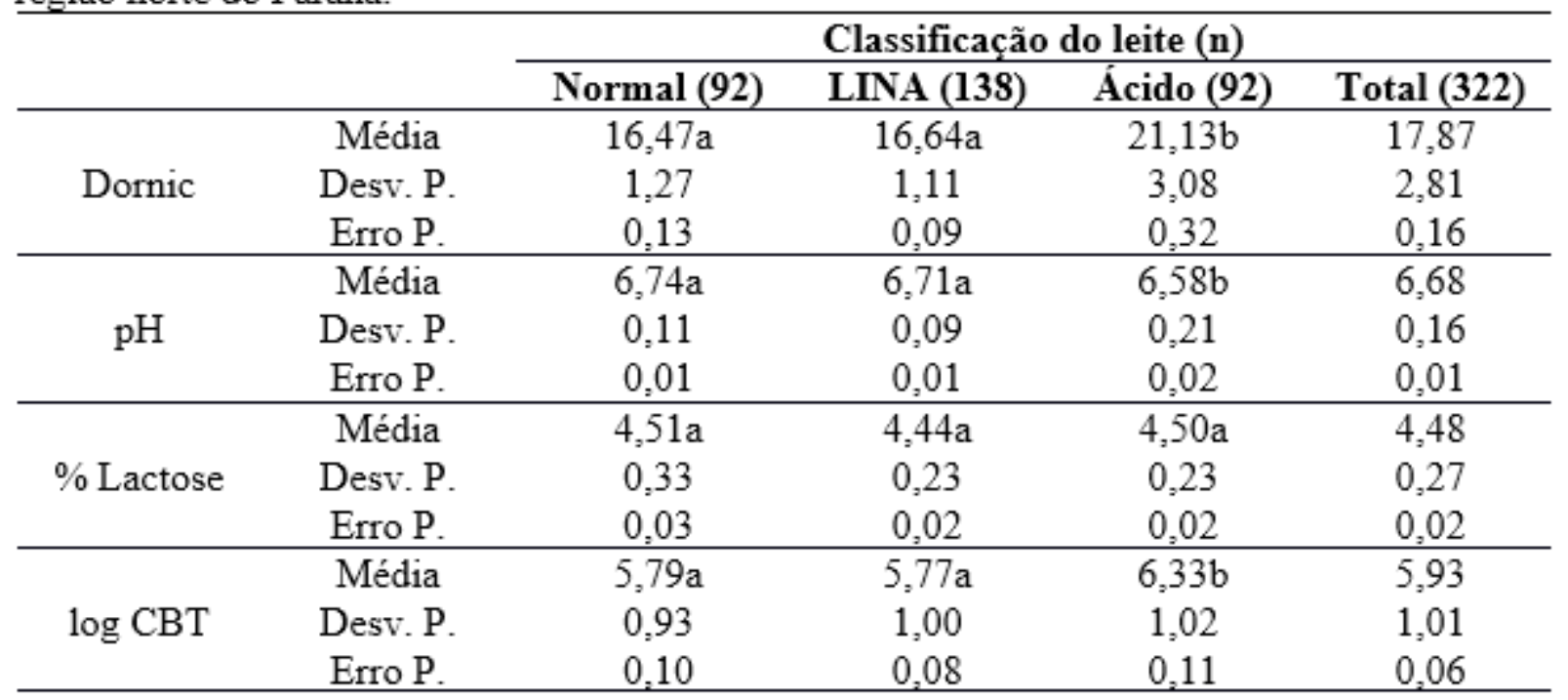

Médias seguidas de letras iguais não diferiram $(\mathrm{p}>0,05)$ pelo teste de Fisher.

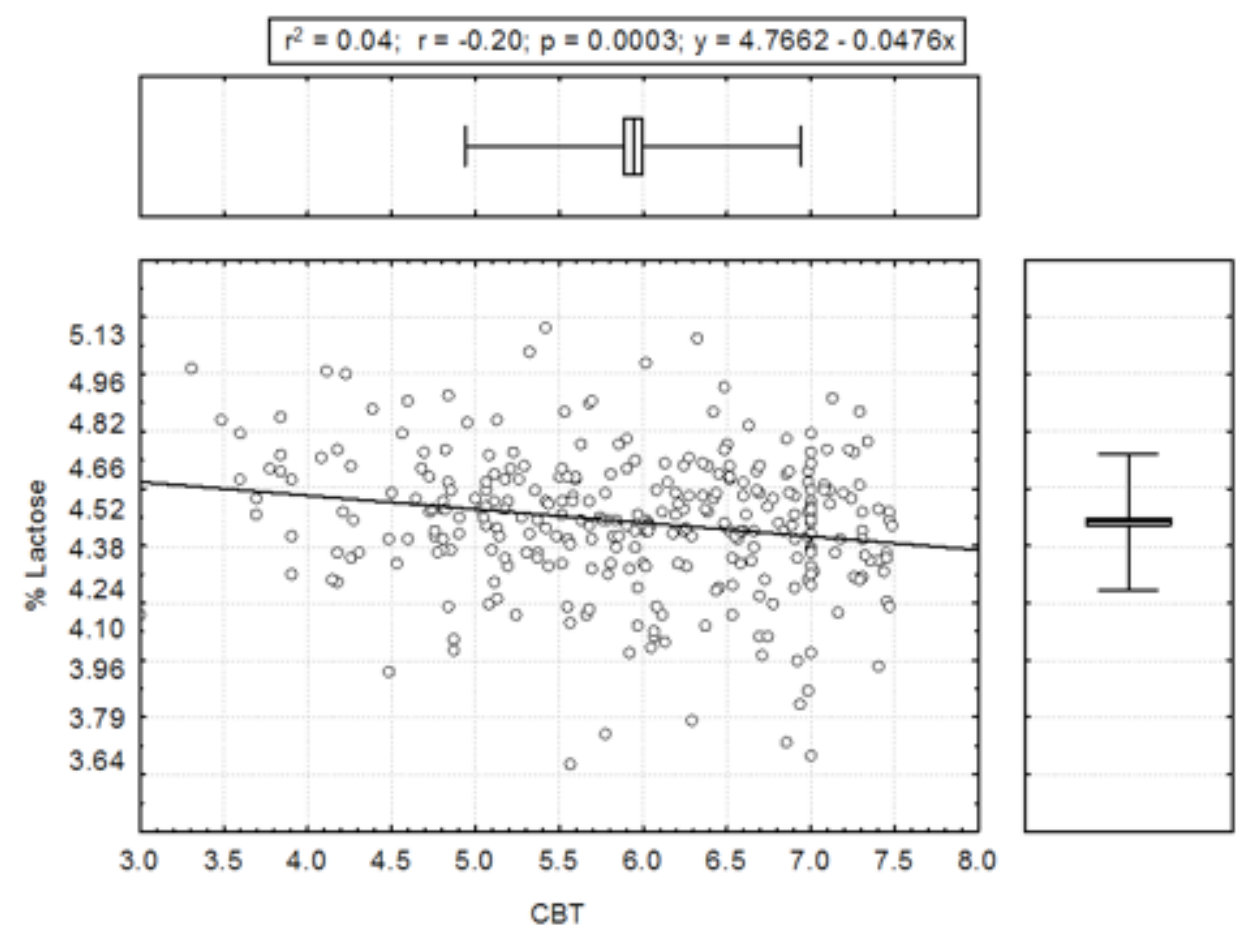

Figura 1: Correlação entre contagem bacteriana total $(\log \mathrm{CBT})$ e porcentagem de lactose em 92 amostras de leite estáveis ao teste do álcool $72^{\circ}$ e sem acidez de origem microbiológica.

Micro-organismos psicrotróficos não degradam a lactose e não produzem acidez titulável no leite, porém são incluídos na contagem bacteriana total pela citometria de fluxo. Neste estudo, apenas os leites que não eram refrigerados foram analisados, tentando descartar esse elemento confundidor. Mesmo assim, como se trata de um estudo de campo, é possível que o produtor tenha misturado e/ou 
congelado o leite amostral e não informou o fato à equipe no momento da coleta.

O leite ácido se comportou de maneira oposta. Todas as variáveis se correlacionaram $(p<0,05)$ entre si (Tabela 2). Assim, acima de 15 graus Dornic, as relações entre a acidez titulável, o pH, a CBT e a porcentagem de lactose são mais evidentes quando comparadas ao leite normal. $\mathrm{O} \mathrm{pH}$ apresentou uma forte correlação negativa com os valores da acidez Dornic $(\mathrm{r}=-0,54)$ e com a CBT $(\mathrm{r}=-0,42)$, ou seja, quanto maior a acidez Dornic menores foram os valores do $\mathrm{pH}$ e maiores as contagens bacterianas (Figura 2). A porcentagem de lactose ainda se correlacionou fracamente com a CBT; entretanto, essa correlação foi mais forte que a correlação encontrada no leite normal, com $r=-0,26$, ou seja, para cada ciclo logarítmico de CBT houve um decréscimo em 0,06\% na lactose (Figura 3).

Tabela 2: Valores dos coeficientes de correlação de Spearman (r) para acidez Dornic, $\mathrm{pH}$, lactose e contagem bacteriana total $(\log \mathrm{CBT})$ de leite ácido da região do norte do Paraná

\begin{tabular}{ccccc}
\hline & Dornic & $\mathbf{p H}$ & \% Lactose & log CBT \\
\hline Dornic & - & $-0.54^{*}$ & $0.06^{*}$ & $0.23^{*}$ \\
$\mathrm{pH}$ & $-0.54^{*}$ & - & $0.06^{*}$ & $-0.42^{*}$ \\
$\%$ Lactose & $0.06^{*}$ & $0.06^{*}$ & - & $-0.26^{*}$ \\
$\log \mathrm{CBT}$ & $0.23^{*}$ & $-0.42^{*}$ & $-0.26^{*}$ & - \\
\hline
\end{tabular}

$* \mathrm{p}<0,05$

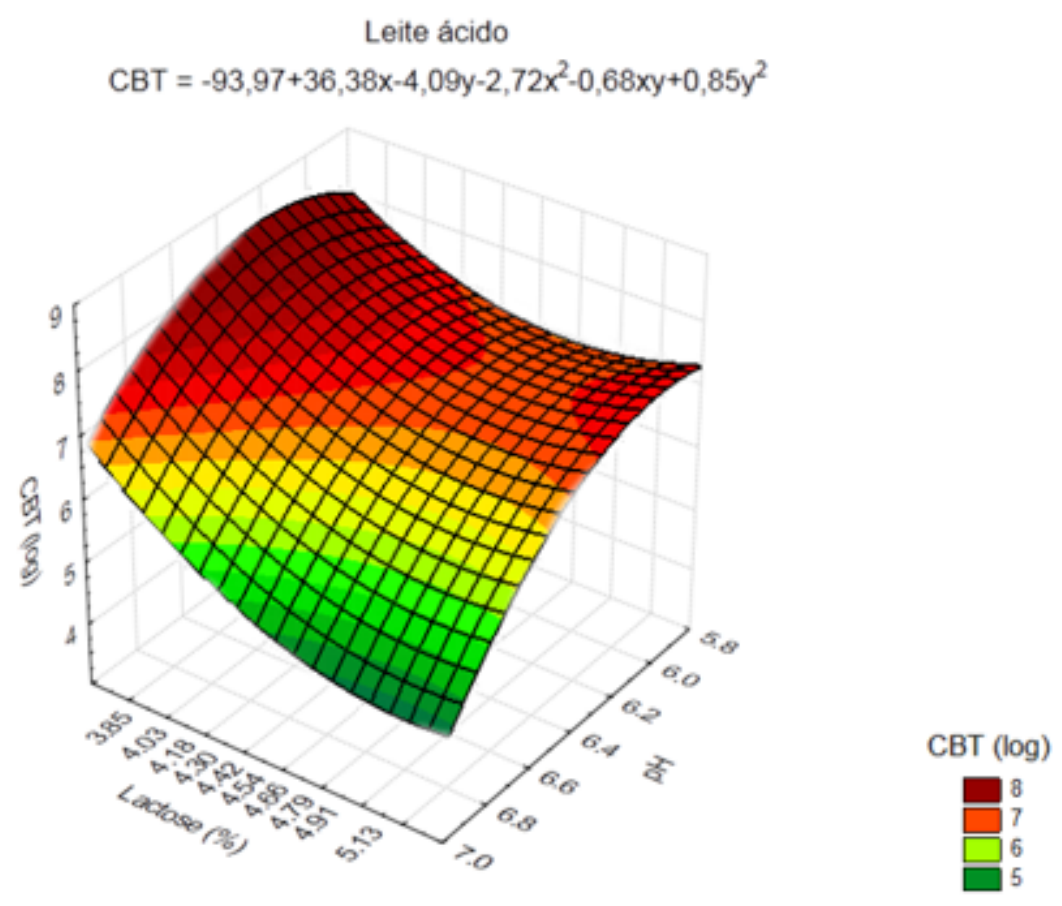

Figura 2: Relação entre a contagem bacteriana $\left(\mathrm{CBT}_{\mathrm{log}}\right)$, porcentagem de lactose e valores de pH em 92 amostras de leite com acidez de origem microbiológica da região norte do Paraná. 


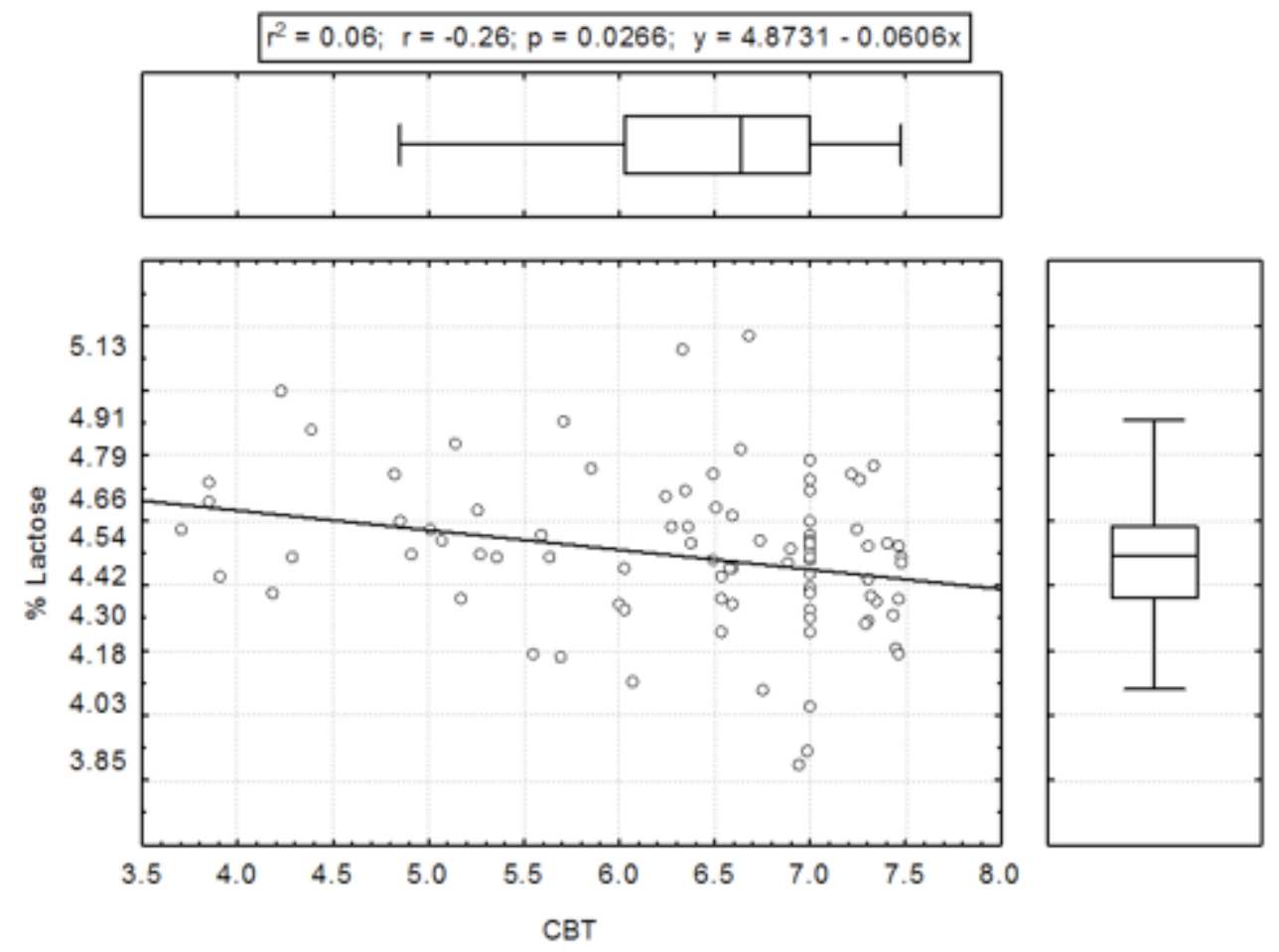

Figura 3: Correlação entre a lactose e contagem bacteriana total (log CBT) em 92 amostras de leite com acidez de origem microbiológica da região norte do Paraná.

A relação entre contagem bacteriana e acidez Dornic foi amplamente estudada em leites de todas as espécies, inclusive em humanos ${ }^{(16)}$. Essa escala serve como parâmetro para a qualidade uma vez que a principal causa de acidez é proveniente da metabolização da lactose em ácido lático por microorganismos aeróbios mesófilos ${ }^{(17)}$.

Dessa forma, ao analisar leites normais e ácidos, a presente pesquisa encontrou a mesma tendência que diversos autores, ou seja, uma estreita correlação entre acidez Dornic, pH e número de microorganismos $^{(18)}$. Mesmo com novos métodos de determinação de acidez em leite, a titulação de ácido lático ainda é um método válido para quantificar indiretamente a qualidade do leite ${ }^{(19)}$.

No entanto, ao analisar a relação entre pH, CBT e acidez Dornic nas amostras classificadas como LINA, o presente estudo não encontrou correlação significativa em nenhuma das variáveis analisadas. Nesse tipo de leite, valores de pH entre 6,6 e 6,8 são acompanhados de contagens bacterianas mais baixas, de até $10^{5}$ bac. $\mathrm{mL}^{-1}$, e porcentagens de lactose mais altas, de até $4,5 \%$. Conforme a CBT aumenta, a porcentagem de lactose ou o $\mathrm{pH}$ tendem a diminuir, porém não necessariamente juntos, como no caso do leite ácido. Esse comportamento dá a forma de canaleta ao gráfico tridimensional (Figura 4).

Algumas pesquisas divergiram ao analisar diferenças no pH entre leites estáveis e instáveis ao álcool. Barros et al. ${ }^{(20)}$ associou LINA à pH's variando em torno de 6,45, atribuindo o fato à relação inversa entre cálcio iônico e pH. Por sua vez, Chavez et al. ${ }^{(13)}$ encontraram instabilidade em $\mathrm{pH}$ 's que variaram em torno de 6,68. Analisando novamente a Figura 4, é possível compreender melhor a divergência entre autores.

Battaglini et al. ${ }^{(6)}$ concluíram que o intervalo de $\mathrm{pH}$ do LINA e do leite normal são semelhantes, independente da estabilidade na prova da fervura, evidenciando que a acidez não é o único fator relacionado à termo-estabilidade do leite. 


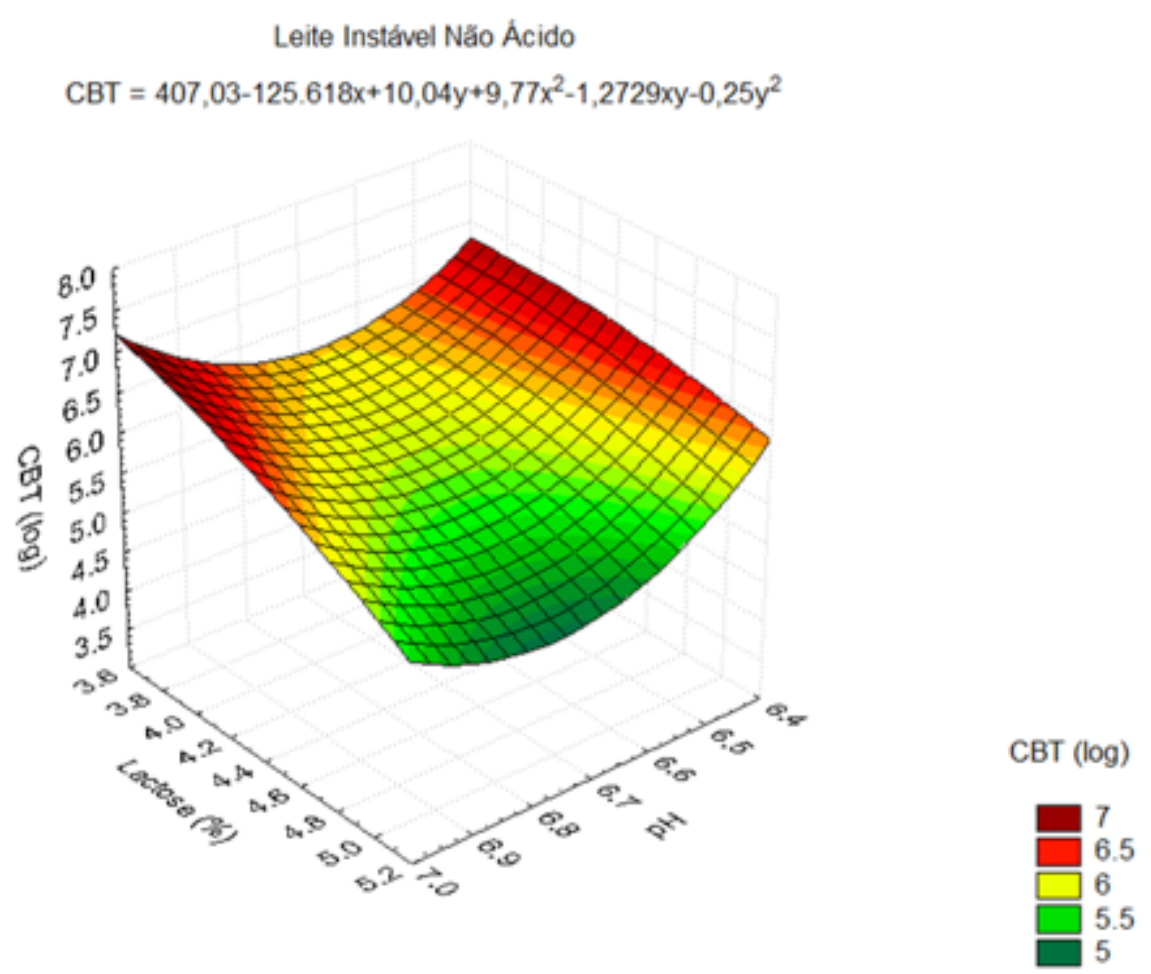

Figura 4: Relação entre a contagem bacteriana $\left(\mathrm{CBT}_{\mathrm{log}}\right)$, porcentagem de lactose e valores de $\mathrm{pH}$ em 132 amostras de leite instável ao álcool $72^{\circ}$ sem acidez adquirida da região norte do Paraná.

Em relação à quantidade de lactose, esse açúcar costuma aparecer em menores concentrações médias no LINA quando comparado ao leite normal. Oliveira e Timm ${ }^{(21)}$, Zanela et al. ${ }^{(22)}$ e Marques et al. ${ }^{(23)}$ encontraram porcentagem de lactose inferior no leite instável mesmo sendo um dos componentes mais estáveis do leite. Esses autores consideraram que a variação da lactose poderia estar associada à energia da dieta e à sanidade da glândula mamária.

A lactose atua no equilíbrio osmótico na passagem dos componentes do sangue para o leite, em conjunto com outros minerais (sódio, potássio e cloro). Assim, com a redução desse açúcar, pode haver maior transporte de minerais para o leite, os quais aumentam a força iônica, reduzem o $\mathrm{pH}$, aumentam a solubilização de cálcio iônico e, por fim, desestabilizam as micelas caseicas ${ }^{(24)}$. A mastite e o estresse também promovem esse mecanismo, mas por diminuírem a força de junção das células epiteliais da glândula mamária ${ }^{(25)}$.

Nem sempre a estabilidade alcoólica depende exclusivamente do $\mathrm{pH}$ e as variáveis que promovem a instabilidade ao álcool nem sempre são as mesmas que promovem a acidificação ${ }^{(26)}$. Assim, o teste do álcool isoladamente pode não ser um indicador confiável para a qualidade do leite ${ }^{(5)}$.

\section{Conclusões}

Diferentemente de leites normais ou ácidos, não existe relação entre pH, CBT e acidez Dornic em amostras de leite que possuem instabilidade alcoólica sem acidez adquirida. Esse comportamento faz com que o teste do álcool não seja um indicador confiável para a qualidade do leite, devendo ser aplicado sempre em conjunto com outras provas que auxiliem no diagnóstico de acidez bacteriana e/ou resistência térmica, como titulação do ácido lático, mensuração de $\mathrm{pH}$ e teste da fervura. 


\section{Referências}

1. Larsen N, Werner BB, Vogensen FK, Jespersen L. Effect of dissolved oxygen on redox potential and milk acidification by lactic acid bacteria isolated from a DL-starter culture. Journal of Dairy Science. 2015;98(3):1640-1651.

2. Brasil. Ministério da Agricultura, Pecuária e Abastecimento. Instrução Normativa $n^{\circ} 62$, de 29 de dezembro de 2011. Diário Oficial da República Federativa do Brasil, Brasília, 30 dez. 2011. Seção 1, p. 6.[Internet] http:// www.apcbrh.com.br/files/IN62.pdf, acesso em maio de 2016.

3. Samaržija D, Zamberlin Š, Pogačić T. Psychrotrophic bacteria and milk quality. MLjekarstvo. 2012;62(2):7795.

4. Tsioulpas A, Lewis MJ, Grandison AS. Effect of minerals on casein micelle stability of cows' milk. Journal of Dairy Research. 2007;74(02), 167-173.

5. Fagnani R, Battaglini APP, Beloti V, Urbano A, de Camargo Bronzol J. Alcohol Stability of Milk from the Perspective of X-Ray Diffractometry. Food Biophysics. 2016;11(2),198-205.

6. Battaglini APP, Beloti V, Fagnani R, Tamanini R, Dunga K. Microbiology and physical chemical characterization of unstable non-acid milk according to the seasons. Revista Brasileira de Medicina Veterinária. 2013;35(1):26-32.

7. Radford SJ, Dickinson E, Golding M. Stability and rheology of emulsions containing sodium caseinate: combined effects of ionic calcium and alcohol. Journal of Colloid and Interface Science. 2004;274(2):673-686.

8. Brasil. Ministério da Agricultura, Pecuária e Abastecimento. Instrução Normativa n ${ }^{\circ} 62$, de 23 de agosto de 2003. Diário Oficial da República Federativa do Brasil, Brasília, 23 ago. 2003. Seção 1.

9. International IDF Standard 141C:2000: Whole milk - determination of milk fat, protein and lactose content. Guidance on the operation of mid-infrared instruments. Brussels, 2000.

10. International IDF Standard 196C:2004: Milk - Quantitative determination of bacteriological quality. Guidance for establishing and verifying a conversion relationship between routine method results and anchor method results. Brussels, 2004.

11. Zanela MB, Fischer V, Ribeiro MER, Barbosa, RS, Marques LT, Stumpf Junior W. Ocorrência do leite instável não ácido no noroeste do Rio Grande do Sul. Arquivo Brasileiro de Medicina Veterinária e Zootecnia. 2009;61(4):1009-1013.

12. Fisher V, Ribeiro MER, Zanela MB, Marques LT, Abreu AD, Machado SC, Stumpf MT. Leite instável não ácido: um problema solucionável. Revista Brasileira de Saúde e Produção Animal. 2012;13(3):838-849.

13. Chavez MS, Negri L, Taverna MA, Cuatrin A. Bovine Milk composition parameters affecting ethanol stability. Journal of Dairy Research. Cambridge. 2004;7(1)120-132.

14. Fagnani R, Battaglini APP, Beloti V. Acid-base balance of dairy cows and its relationship with alcoholic stability and mineral composition of milk. Pesquisa Veterinária Brasileira. 2014;34(5):398-402.

15. Sand KK, Rodriguez-Blanco JD, Makovicky E, Benning LG, Stipp SLS. Crystallization of CaCO3 in water-alcohol mixtures: spherulitic growth, polymorph stabilization, and morphology change. Crystal Growth \& Design. 2011;12(2)842-853.

16. Novack F, Cordeiro DMB. The correlation between aerobic mesophilic microorganism counts and Dornic acidity in expressed human breastmilk. Jornal de Pediatria. 2007;83(1). 
17. Alegría Á, González P, Delgado S, Flórez AB, Hernández-Barranco AM, Rodríguez A, Mayo B. Characterisation of the technological behaviour of mixtures of mesophilic lactic acid bacteria isolated from traditional cheeses made of raw milk without added starters. International Journal of Dairy Technology. 2016;69:1-13.

18. Donatele DM, Vieira LFP, Folly MM. Relação do teste de Alizarol a $72 \%$ (v/v) em leite in natura de vaca com acidez e contagem de células somáticas: análise microbiológica. Revista Higiene Alimentar. 2003;17:95100.

19. Fabro MA, Milanesio HV, Robert LM, Speranza JL, Murphy M, Rodríguez G, Castañeda R. Determination of Acidity in Whole Raw Milk: Comparison of Results Obtained by Two Different Analytical Methods. Journal of Dairy Science. 2006;89(3):859-861.

20. Barros L, Denis N, Gonzalez A, Nuñez A. Ionic calcium related to alcohol test in milk. Prácticas Veterinárias. 1999;9(1):315-318.

21. Oliveira DS, Timm CD. Composição do leite com instabilidade da caseína. Ciência e Tecnologia de Alimentos. 2006;26(2)259-263.

22. Zanela MB, Fischer V, Ribeiro MER, Barbosa, RS, Marques LT, Stumpf Junior W, Zanela C. Leite instável não-ácido e composição do leite de vacas Jersey sob restrição alimentar. Pesquisa Agropecuária Brasileira. 2006;5:835-840.

23. Marques LT, Zanela MB, Ribeiro ME, Stumpf Júnior W, Fischer V. Ocorrência do leite instável não ácido (LINA) e seu efeito sobre a composição química e aspectos físicos. Revista Brasileira de Agrociência. 2007;13(1):91-97.

24. Horne DS, Muir DD. Alcohol and heat stability of milk protein. Journal of Dairy Research. 1990;46(3):433439.

25. Stelwagen K, Hopster H, Van Der Werf JTN. Short communication: effects of isolation stress on mammary tight junctions in lactating dairy cows. Journal of Dairy Science. 2000;83(1):48-51.

26. Lewis MJ. The measurement and significance of ionic calcium in milk-a review. International Journal of Dairy Technology. 2011;64(1):1-13. 